the system in the ventricular septum were also severely affected, further establishing the aetiology of the heart block.

These findings are characteristic of the lesions and the functional impairment that

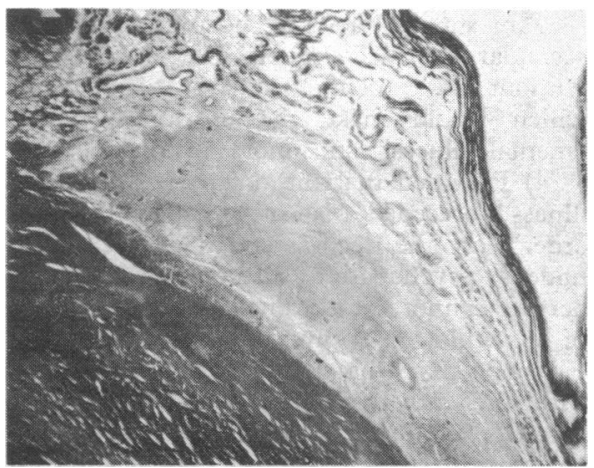

Fig 2-The rode of Tawara, recognizable above the dark-stained central fibrous body, almost completely

seems to be peculiar to sarcoid heart disease, as stated in your leading article.-I am, etc.,

Columbus Clinic

Lino Rossi

1 Ghosh, P., Fleming, G. A., Gresham, G. A., and Stovin, P. G. I., British Heart fournal, 1972 , 34, 769 .

Rossi, L., Histopathologic Features of Cardiac
Arrhythmias, p. 143. Milan, Casa Editrice Ambrosiana, 1969.

\section{Cutaneous Sarcoidosis in Venepuncture} Sites

SiR,-Dr. B. W. Hancock (23 December, p. 706) reports six cases of sarcoidosis which first showed itself by the development of granulomas at the site of previous venepunctures for blood donation. This phenomenon must be an extremely rare one. In a personal series of 260 cases of sarcoidosis, seen over a period of 25 years, there have been 20 examples of granulomatous involvement of cutaneous scars, only one of which related to a venepuncture site.

A woman aged 59 presented in 1969 with typical erythema nodosum on the shins associated with bilateral hilar lymphadenopathy, and the Kveim test gave a positive reaction. She had not been a blood donor. Ten years previously she had been treated for anaemia with a series of iron injections, some of which had been administered intramuscularly into the buttocks and some intravenously into the left antecubital veins. During the five months preceding the appearance of the erythema nodosum she developed two painful prominent red nodules in the scars overlying the site of the previous intravenous injections, and two weeks before the erythema nodosum appeared she also developed deep tender nodules in the gluteal muscles. She was not given corticosteroid therapy. The erythema subsided in six weeks and the bilateral hilar adenopathy after six months, and during this time the left antecubital skin nodules also subsided. Biopsy was not carried out on the cutaneous nodules, but there could be little doubt that this was an example of sarcoid granulomatous involvement of scar tissue both in the gluteal muscles and in the skin over the left antecubital veins.

The granulomatous involvement of scars in the course of sarcoidosis appears to occur chiefly where the scars are relatively old and firm (and possibly containing particles of silica) and not where there has been merely some recent minimal skin trauma. Patients with sarcoidosis, during their investigation, are invariably subjected to diagnostic tests including venepuncture, yet sarcoid granulomas do not develop at the sites of these venepunctures. The explanation for the phenomenon among blood donors may well be that in this procedure a local anaesthetic is usually introduced into the skin over the vein, a large-bore needle is used and remains in the vein for a longer period, and the same site is often used for successive blood donations. Hence the greater trauma to the veins and extravasation of blood and its subsequent organization lead to more scarring than occurs after the relatively trivial trauma involved in simple diagnostic venepuncture. Moreover, the blood donor needle would in the past have been used repeatedly, and been sharpened on a grinding stone which might have left the slightest trace of silica or some other element on it. The scarring resulting from some of the iron preparation finding its way outside the vein would also explain the phenomenon in the case described above.

The speculation by Dr. G. MacGregor in his letter (10 February, p. 357) as to whether "an intracutaneous injection of saline (or of the patient's blood) [might] be as effective in diagnosing early sarcoidosis as an injection of Kveim homogenate" has already been answered by the work of Refvem ${ }^{1}$ and also of Hurley and Shelly ${ }^{2}$, who performed intracutaneous tests with numerous substances (including beryllium, silicon, etc) as well as with homologous blood and found no evidence of a granulomatous reaction in a large series of sarcoidosis patients and normal controls, thus disposing of the theory of the terrain sarcoïdique or sarcoid diathesis as an explanation of the aetiology of sarcoidosis. I am, etc.,

Alex Sakula

Redhill General Hospital,

Surrey

Refvem, O., Acta Medica Scandinavica, 1954, 149, Suppl. 294

Hurley, H. J., and Shelley, W. B., American
fournal of the Medical Sciences, 1959, 237, 685.

SIR,-We were very interested to read the description by Dr. B. W. Hancock (23 December, p. 706) of six patients who developed sarcoid granulomata at the site of previous venepunctures. We have recently studied a woman who developed sarcoid granulomata at the sites both of venepunctures and of previous intravenous infusions.

The patient was a woman aged 32 who had been well until July 1970, when she developed attacks of abdominal pain while in the Middle East. A laparotomy was carried out, at which the spleen was found to be grossly enlarged and was removed. A diagnosis of brucellosis was made (brucella antibodies being positive to a titre of $1 / 160$ ) After the operation she returned to the U.K. but continued to experience attacks of abdominal pain, for which she attended hospital between April and October 1971 and was investigated with negative resul's, chest $x$-ray, barium studies, and intravenous pyelogram all being normal.

In June 1972 she noticed a lump in the right axilla and at about the same time became increasingly tired and breathless on exertion, with soreness of the eyes and recurrent abdominal pain. Phvsical examination showed enlarged axillarv, preauricular, submaxilliary, and submental lymph nodes.
The conjunctivae were inflamed and fine crepitations were heard at the lung bases. (A chest $x$-ray showed bilateral hilar adenopathy and parenchymal involvement.) Small skin nodules were present at sites of previous venepuncture in the left antecubital fossa and also at several other sites on the arms and feet where she had had intravenous infusions during her illness in 1970. Histological examination of one of these skin nodules and of an axillary lymph node and the site of a Kveim test all showed typical sarcoid granulomata.

After one month on corticosteroid therapy her symptoms of malaise, breathlessness, and abdominal pain have improved somewhat but there has been no change in the appearance of the skin nodules.-We are, etc.,

R. F. HARVEY

J. VERRIER JONES

H. J. O. WHITE

Southmead Hospital,

Southmeal
Bristol

SIR, - With reference to Dr. G. A. MacGregor's letter (10 February, p. 357), we should like to correct his unwarranted assumption that the histology of erythema nodosum in patients with sarcoidosis represents deposits of sarcoid granulomas. If one carries out a biopsy on a late stage of erythema nodosum, irrespective of its cause, one finds small follicular granulomas of foreign-body type, which develop in relation to the fat necrosis.-We are, etc.,

IAN A. SHORT JOHN A. MILNE

Glasgow

Western Infirmary,

\section{Gastric Decompression after Abdominal} Surgery

SIR,-Your leading article on gastric decompression (27 January, p. 189) deals admirably with a much-discussed problem. Probably there will never be complete agreement on the precise indications for decompression, but I believe that when decompression is necessary the case for gastrostomy rather than nasogastric aspiration is overwhelming. I have used gastrostomy routinely in preference to a Ryle's tube since 1964 in every patient (a total of 200-300) in whom at operation I have expected would need postoperative decompression.

I have never seen an infected gastrostomy wound. I use a whistle-type catheter brought through a separate stab wound. The main incision is dressed separately and is devoid of drains, stomata, or any other extraneous foreign bodies. There is no obvious reason why a clean gastrostomy should cause this to be infected, nor do I find an unduly high incidence of this complication. I have no detailed records on the incidence of postoperative chest infections, but anaesthetists have welcomed the absence of a Ryle's tube in patients needing postoperative ventilation, and physiotherapists and nurses find it easier to treat patients who have a gastrostomy.

Patients who have had both gastrostomy and nasogastric decompression invariably say that they would never again have a Ryle's tube postoperatively. It is salutary to see a patient drinking tea the day after 